\title{
A estética do sopro em Clarice Lispector e o gozo feminino
}

The aesthetics of the breath in Clarice Lispector and the feminine jouissance

La estética de la respiración en Clarice Lispector y el gozo femenino

Cristina Moreira Marcos*

\begin{abstract}
Resumo
A arte nos ensina modos de subjetivação que estão em jogo na clínica. É a partir do que chamo de uma estética do sopro, pelos murmúrios e intervalos da escrita, que algo sobre o feminino se dá a ler, permitindo aproximar o que Lacan descreve como gozo feminino e a sublimação. A escrita é pensada como certo destino contingente do feminino impossível, suporte do gozo suplementar, tendo relação com o falo e com S (do Outro barrado). Minha intenção é ler, em Clarice Lispector, não uma significação feminina da obra, mas as questões colocadas pela obra em relação ao feminino. Neste artigo, abordo o livro "Água Viva” como um discurso teórico que fornece modos de leitura da obra de Clarice Lispector, graças à natureza singular do saber que aí se constitui.
\end{abstract}

Palavras-chave: Feminino, Estética do sopro, Sublimação, Gozo feminino.

\begin{abstract}
Art teaches us ways of subjectiveness that are the object of clinical practice. We can read from something about the feminine pertaining to what I propose to call an "aesthetics of the breath", from the murmur and the blanks of the writing, so as to allow approximation to what Lacan calls the feminine jouissance and the sublimation. Writing is thought of as a certain contingent fate of the impossible feminine, giving support to a supplementary jouissance and having a relation with the phallus and the $S(A)$. I intend to read in Clarice Lispector the questions her work raises about the feminine, and not a feminine signification of her work. The theoretical framework is provided by her book "Água Viva".
\end{abstract}

Keywords: Feminine, Aesthetics of the breath, Sublimation, Feminine jouissance.

\footnotetext{
* Doutora em Psicanálise pela Universidade de Paris VII, mestra em Literatura Brasileira pela UFMG, docente do Programa de Pós-graduação em Psicologia da PUC Minas, psicanalista. Endereço: Rua Paschoal Carlos Magno, 68 - Bairro Ouro Preto, Belo Horizonte-MG. CEP: 31310-510. Telefones: (31) 3498-4182 e 9163-4073. E-mail: cristinammarcos@gmail.com.

Este artigo é parte da minha tese de doutorado intitulada "L'esthétique du souffle chez Clarice Lispector: un certain destin du féminin”, defendida em Paris VII, sob orientação do Prof. Dr. Patrick Guyomard.
} 


\section{Resumen}

El arte nos enseña formas de subjetividad que están en juego en la clínica. Es a partir de lo que yo llamo una estética de la respiración, por murmullos e intervalos de la escritura, que algo sobre lo femenino pasa a ser leído, lo que permite aproximarse a lo que Lacan describe como gozo femenino y sublimación. La escritura se piensa como cierto destino contingente de lo femenino imposible, soporte del gozo suplementario, relacionándose al falo y a $S$ (del Otro impedido). Mi intención es leer, en Clarice Lispector, no una significación femenina de la obra, sino las preguntas planteadas por la obra en relación con lo femenino. En este artículo, discuto el libro "Agua Viva" como un discurso teórico que ofrece maneras de lectura de la obra de Clarice Lispector, gracias a la naturaleza singular del saber que ahí se constituye.

Palabras clave: Femenino, Estética de la respiración, Sublimación, Gozo femenino.

M inha intenção é ler, em Clarice Lispector, não uma significação feminina da obra, mas as questões colocadas pela obra em relação ao feminino. É pelo que chamei de uma estética do sopro, pelos murmúrios e intervalos da escrita que algo sobre o feminino se dá a ler. Neste artigo, abordo o livro "Água Viva" (Lispector, 1973) como um discurso teórico que fornece modos de leitura da obra de Clarice Lispector, graças à natureza singular do saber que aí se constitui. Não submetido às regras da razão, ele leva a linguagem a um território próximo do impossível e do inominável, da contradição e do paradoxo. Este saber se diz em uma outra língua, "lalangue", e é aí que algo sobre o feminino se pode ler.

O caráter múltiplo e atemático de “Água Viva” exige a construção de um novo modo de leitura, algo a ser inventado, não de uma vez por todas, mas a ser recriado a cada leitura. Esse livro exige uma leitura compatível com sua escrita (algo incessantemente renovado e relançado e sempre inacabado). Tal é a natureza do saber que se constitui em "Água Viva” (um saber sem repouso, sem conclusão, em suspensão, interditando assim qualquer leitura interpretativa).

Estou te falando em abstrato e pergunto-me: sou uma ária cantabile? Não, não se pode cantar o que te escrevo. Por que não abordo um tema que facilmente poderia descobrir? Mas não: caminho encostada à parede, escamoteio a melodia descoberta, ando na sombra, nesse lugar onde tantas coisas acontecem. [...] 
A melodia seria o fato. Mas que fato tem uma noite que se passa inteira num atalho onde não tem ninguém e enquanto dormimos sem saber de nada? Onde está o fato? Minha história é de uma escuridão tranquila, de raiz adormecida na sua força, de odor que não tem perfume. E em nada disso existe o abstrato. É o figurativo do inominável (Lispector, 1973, p. 215).

Em “Água Viva”, o leitor é convidado a seguir o fluxo contínuo das palavras sem buscar por atrás uma verdade clariciana. Atrás do véu da representação, não há nada. A escrita faz aqui o voto de que a linguagem seja não véu, mas potência que desnuda as palavras. Não há, portanto, uma significação final, mas a transparência, o nada que há por trás do véu. Esse desvelamento poderia se dizer feminino, sem uma significação final, sempre fálica, no qual o nada se afirma como presença, e a representação não se quer nem simbólica, nem imaginária, podendo ser definida como mostração ou apresentação. Da ordem do feminino, ela não perseguiria a significação última, seu modo de existência seriam fugazes instantes, o que se ouve como murmúrio, sussurro, sopro, o que vai e vem, inapreensível.

Talvez venha daí um mal-estar provocado pelas palavras e um lamento lançado: se eu pudesse escrever por intermédio de um desenho ou de um carinho na cabeça de uma criança ou, simplesmente, se eu pudesse não escrever. Trata-se de uma escrita que quer se desvencilhar das palavras.

Eis que percebo que quero para mim o substrato vibrante da palavra repetida em canto gregoriano. Estou consciente de que tudo o que sei não posso dizer, só sei pintando ou pronunciando sílabas cegas de sentido. E se tenho aqui que usar-te palavras, elas têm que fazer um sentido quase que só corpóreo, estou em luta com a vibração última (Lispector, 1973, p. 14).

Como seria possível uma representação que não é nem da ordem da imagem, nem da ordem do significante, enviando-nos, portanto, a um além do falo e a um além do simbólico, e que permanece sendo da ordem da escrita? A narradora é uma pintora que deixa seus pincéis (a arte pictórica, que seria uma arte da mostração, em todo caso, mais do que a literatura) para se dedicar às palavras.

Se a literatura é a arte do dizer, a "lituraterra" não seria a arte do que se mostra, do que se dá a ver? Falando de literatura, Lacan descreve o sobrevoo que ele fez da planície siberiana, fala de como esse território se oferece ao olhar e de como as rasuras e as erosões constituem uma escrita a ler: "A escrita é esse ravinement" (Lacan, 1987). Ora, a escrita de Clarice nos pede esse voo do olhar. "Este texto que te dou não é para ser visto de perto: ganha sua 
secreta redondez antes invisível quando é visto de um avião em alto voo. Então adivinha-se o jogo das ilhas e veem-se canais e mares" (Lispector, 1973, p. 58).

A escrita de Clarice nos permite colocar em relação à letra e à voz e pensar esta última para além da oralidade. Trata-se de um caminho em direção a uma outra dimensão da escrita, aquela que quer escrever o objeto. Reduzir a palavra à sua materialidade, inscrever a voz na escrita não como significação ou signo linguístico, mas como objeto (tais parecem ser os votos dessa escrita, que poderíamos chamar não de escrita do significante ou do significado, mas do objeto). “A palavra é objeto?” (Lispector, 1973, p. 19), pergunta-se Clarice.

O elemento vocal é fundamental no esforço de escrever a dura escritura, a palavra toma os modos de uma coisa, de um objeto. Há uma lapidação do som, do ritmo, da voz. Trata-se de seguir os traços e os efeitos de um ravinement que parece ser fazer pela respiração. A sonoridade é muito mais buscada do que o sentido ou a narrativa, e o narrador nos pede uma escuta que se deixe conduzir pela música das sílabas disjuntas do sentido. "Água Viva" coloca em cena o que insiste e o que se repete na obra de Clarice: o sopro e a respiração.

"Água Viva" não é outra coisa senão o fluxo contínuo das palavras e das frases que não terminam nunca. "O que eu te escrevo continua e eu estou enfeitiçada", escreve Clarice ao final do livro. A busca de um sentido ou de um ponto de parada a partir do qual o sentido se ordenaria é um vão esforço. Que nos deixemos ser capturados pelas palavras (este é o convite do texto). Que sigamos o ritmo e a sonoridade das palavras sem buscar uma significação final. Que escutemos os traços da fuga de sentido no texto. Trata-se, em suma, de um esvaziamento do sentido. O que surge como resto caído desta operação é a voz.

Claro, é paradoxal falar de voz já que se trata de textos escritos, de textos que se dão a ler. Entretanto, seus tons, seus murmúrios, seus silêncios, seu esforço para alcançar um além da literatura, a música, permitem-nos falar da voz. O paradoxo está no centro desses textos, pois se trata de voz escrita, sempre em falta em relação ao que se quer ser. Daí a respiração, o silêncio, o branco que impregnam o texto de um tom, de uma certa gravidade da voz.

Respirar é a arte do ravissement. O ravissement é a ausência do sujeito, como na síncope, o sujeito não está lá como numa espécie de mimetismo da morte. Entretanto, imita-se a morte para não morrer e volta-se desse além com uma lembrança singular. Pertencem à esfera da síncope as manifestações corporais simples, que suspendem a respiração, tais como a tosse, o espirro, 
o soluço, a asma, o grito, as lágrimas (Clément, 1990). São banais sufocos cotidianos, mas, espasmódicos, eles provocam uma suspensão do ser. $\mathrm{O}$ que não pode se calar escapa, irreprimível, suspende a respiração, rompe a palavra. Poderíamos dizer que as rupturas, os intervalos, os gemidos na escrita de Clarice Lispector correspondem a esses estremecimentos corporais.

Em "Um sopro de vida", Ângela, protagonista do livro, é "a que brame, muge, geme, resfolega, balindo e rosnando e grunhindo" (Lispector, 1999, p. 31). Seus gemidos são os substitutos das lágrimas, são lágrimas internas, mais sonoras do que visuais, que tornam o silêncio sensível (Charvet, 2000, p. 65). Os gemidos, como as lágrimas, interrompem o discurso, impõem o silêncio, são como a pontuação de uma frase, a respiração transfigurandose em discurso. Os gemidos de Ângela ameaçam sua linguagem, situando-a nas bordas do indizível, entre as palavras e o silêncio.

Como representar o gemido, esse grito do silêncio, essa lágrima interna que se faz ouvir mais do que se faz ver, essa interrupção do discurso cujo verdadeiro lugar seria uma além da linguagem? A arte de Clarice coloca incessantemente essa questão e parece atingir esse ponto no qual as lágrimas, os gemidos e os gritos suspendem o sentido e transformam-se eles mesmos em linguagem. É a eloquência do silêncio que fala, como na música barroca, na qual as lágrimas chegam à sua expressão máxima, impondo o silêncio, as pausas, as interrupções. Ângela é barroca, ela é eloquência e silêncio, excesso e falta, vida e morte.

As constantes alusões à música fazem parte de uma mesma concepção da arte: que a música seja essa linguagem sem palavras, que a pintura seja livre de toda figura e que a escrita seja o mais próxima possível do balbucio, da respiração, do sopro. "Atrás do pensamento" não há palavras, nem raciocínio, há um fundo musical. A referência à música em Clarice Lispector atesta a busca impossível de uma voz para sempre perdida, de uma linguagem que seria equivalente ao canto perdido.

Ângela é esse território da ausência do pensamento, de antes da linguagem: "atrás do pensamento", ela não diz nada, como a verdadeira música não tem palavras. "Atrás do pensamento", ela é plena de pré-palavras e tem visões auditivas de ideias. Temos aí todo o paradoxo dessa escrita que quer atingir um além da linguagem pela linguagem ela mesma. "Ângela Pralini é, às vezes, desvencilhada e suavemente aguda como as vozes de meninos cantores executando cantatas de Bach, ou coro de monges. Ângela é meu exercício vocal" (Lispector, 1999, p. 133). 
Múltiplas são as referências à música como representante desse além da linguagem, a escrita podendo ser tomada como uma nostalgia da música. Segundo Pascal Quignard (2000), a invenção do tempo humano resume-se à invenção da narrativa, ao passo que a invenção da melodia não é humana e precede o tempo do humano. A escrita seria assim um esforço para se escapar do tempo e para sair da narrativa. Certo, é impossível subtrair-se à temporalidade da narrativa, mas escrever é entrar em contato com o voto do silêncio, com o tempo, no qual os sons não pretendiam dar um sentido ao mundo, no qual eles não tinham sido elevados ao status de linguagem. Por isso, o escritor pode ser definido como "aquele que fez o paradoxal voto de silêncio", o voto de permanecer fiel ao vazio primordial da linguagem. Ele é aquele que fala calando-se. Escrever é esse "falar mudo, espreitar a palavra que falta [...] é escutar a voz perdida" (Quignard, 2000, p. 62).

Um romance sem narrativa, um livro sem palavras, tal é a ambição de Clarice. "Água Viva” ou ainda "Um sopro de vida” são comparados à música, à improvisação do jazz, à música de câmara. A música, essa linguagem esvaziada de sentido, figura como ideal a ser atingido. "Ângela é o tremor vibrante de uma corda tensa de harpa depois de tocada: ela fica no ar ainda se dizendo, dizendo - até que a vibração morra espraiando-se em espumas pelas areias. Depois - silêncio e estrelas" (Lispector, 1999, p. 45).

Ângela é trêmula, e as palavras que saem de sua boca trêmula também o são. "Ela tem que deixar de ser tão hesitante porque senão vai ser um livro todo trêmulo, uma gota d'água pendurada quase a cair e quando cai divide-se em estilhaços de pequenas gotas espalhadas" (Lispector, 1999, p. 36). Como as lágrimas que escorrem, como os lábios antes de dizer a palavra procurada, como a boca antes do gemido, Ângela é a voz que treme. Tensa, tomada nesse momento do antes, do quase, da beira, ela parece estar sempre em direção ao apagamento, no caminho de se calar. Vacilante, chancelante, como a flama de uma vela, Ângela é ao final da respiração. O livro será trêmulo, disperso em uma multidão de itálicos, de parênteses, de brancos, de pontos de exclamação.

Os terremotos destroem as civilizações, cavam buracos gigantes sob o solo, abalam civilizaçóes. Um sopro de vida abala as categorias e os gêneros literários, faz vacilar o solo sob nossos pés e faz de nós seres perdidos, sem terra firme, sem ponto de referência. Os terremotos abrem buracos, fendas, abismos, grutas. Os terremotos dão lugar às ruínas.

O “autor", em "Um sopro de vida”, escreve sob ruínas, e Ângela fala de grutas e de cavernas pré-históricas. Para Clarice, a gruta é seu "mergulho na terra", no mundo primitivo, habitat e refúgio dos animais iguais a eles 
mesmos desde a Pré-história (os ratos, os morcegos, as aranhas, os escorpiões, as baratas). A gruta é o útero do mundo, o lugar da vida em seu estado bruto, vida de matéria elementar. Como colocá-la em palavras sem a descrever?

A gruta é também orelha, lugar onde ressoa o som, a voz. Como escutar essa voz que vem das cavernas, voz ancestral, anterior à linguagem, senão pelo seu eco mesmo, que é também palavra, por essa voz que ressoa e se perde, intocável? $\mathrm{O}$ eco não é o equivalente da imagem refletida no espelho, ele não é um duplo que nos reenvia uma imagem de nós mesmos, localizável e simétrica. O eco é não é situável, ele desaparece tão logo alguém se aproxime. Para escutá-lo é preciso aceitar a escuridão das cavernas, esse mundo primitivo e subterrâneo.

Segundo Pascal Quignard, a língua é, para os seres falantes, a casa deles. Não são os mares ou as grutas que fazem as habitações dos homens, mas "a voz que trocam entre eles e seus sotaques singulares" (Quignard, 1996, p. 39). Assim a voz é a casa dos homens e também assim o "autor" de "Um sopro de vida" pode dizer do seu personagem (sua voz): "Ângela é minha moradia".

Nesse lugar obscuro, amorfo e úmido como uma caverna primitiva, não se pensa. Falar dele exige a alusão, toda abordagem direta é impossível. Por isso Ângela é oblíqua, de viés, trêmula. Ela é uma atmosfera indizível, intransmissível, inexorável, impossível de capturar, ela escapa. Ela é indireta. "Eu sou oblíqua como o voo dos pássaros. Intimidada, sem forças, sem esperança, sem avisos, sem notícias - tremo - toda trêmula. Me espio de viés" (Lispector, 1999, p. 37).

Ângela pode se dar a ver somente de viés, obliquamente. Não é desse modo que o feminino encontra seu modo de existência? Falando dos territórios da pulsação, lugar da mãe, Ângela nos fala dessa parte em nós que nos excede, que escapa ao simbólico, ela nos fala de um não lugar que a exila dela mesma, constituindo uma alteridade radical: "Eu sou como estrangeira em qualquer parte do mundo. Eu sou do nunca" (Lispector, 1999, p. 57).

$\mathrm{O}$ que não pode ser alcançado ou abordado diretamente, que exige um desvio, que nos faz vacilar, hesitar, tatear. O que não tem duplo, nem imagem, que não é simétrico e que não garante nenhuma harmonia. $\mathrm{O}$ que assinala sempre um resto, um dejeto, um pedaço inacessível, que permanece excessivo ou pouco. É isso ser indireta, oblíqua e de viés.

Essa delicada realidade, efêmera e sutil, seria o modo de existência possível do feminino. O aforismo lacaniano "A mulher não existe" significa que o significante próprio para dizer a mulher, não como outro sexo, ou seja, em 
relação ao homem e à castração, mas como um sexo, não existe no inconsciente. Lacan mantém o falocentrismo da sexualidade, o que quer dizer que só há um sexo no inconsciente, o falo, e que não há essência feminina. Para todo ser falante, o sexo feminino é Outro, o Outro absoluto.

No seminário "Encore", Lacan (1975) propõe apreender a mulher a partir de sua não aderência completa à castração, mesmo se ela não é sem referência à castração, ela não é toda fixada aí. Podemos dizer que é sobre esta hipótese que Lacan funda toda sua interpretação sobre a mulher e o feminino. As mulheres não são inteiramente situadas, "não toda", do lado do falo, mas também não são sem relação com o falo. Daí a dualidade do gozo para elas, de um lado orientado em direção ao falo, o que corresponde ao gozo fálico, regulado pela castração, e, de outro lado, em direção ao significante da falta no Outro S (de A barrado), correspondendo ao gozo suplementar.

Entretanto, esse gozo suplementar, avançado com muita prudência por Lacan, não é mais do que uma suposição, se ele existe, dele as mulheres não podem dizer nada. Esse gozo só pode encontrar existência numa realidade suspeitada e só pode se dizer do modo oblíquo como nos fala Clarice.

Ângela é o excesso. Incomparável, estrangeira, ela ultrapassa o que se pode dizer. Ângela é fora da linguagem, orgânica, ela é fora de si. "Angela é orgânica. [...] Além dela que mal vejo, além dela começa o que não sei dizer. [...] Ela é as palavras que esqueci” (Lispector, 1999, p. 58). Ela é o eco inarticulável de um sujeito desconhecido dele mesmo, as palavras que esqueço, a lembrança do momento em que a língua me abandona, no qual seu fracasso e seu limite se fazem sentir, no qual eu me sinto petrificado pela ausência da língua que se manifesta em mim. Ângela é o nome sob a ponta da língua, lembrando-nos de que a língua em nós é adquirida e que ela pode nos abandonar (Quignard, 2000, p. 67). “[...] essa parte escura de mim e que é vital, sem ela eu seria vazio. [...] Ângela é do meu interior escuro: ela porém vem à luz" (Lispector, 1999, p. 73). Ângela é a memória daquilo que não se lembra. Ela é a nostalgia de um tempo antes da linguagem. Clarice nos fala dessa ausência, dessa sombra, desse vazio primeiro.

Clarice quer permanecer fiel a essa falta primordial que constitui todo ser falante, a essa nostalgia originária, a essa voz que se perde e cai por trás da significação das palavras, a esse silêncio inaugural que funda as palavras. Entretanto, Clarice pode existir somente na linguagem, Ângela é seu esforço para reencontrar o canto perdido. Sua busca consiste em procurar a linguagem onde ela vacila, onde a palavra falta e o real se faz sentir. Sua escrita só se pode escrever pelo fracasso da linguagem. "Por destino tenho que ir buscar e por 
destino volto com as mãos vazias. Mas volto com o indizível. $\mathrm{O}$ indizível só me poderá ser dado através do fracasso de minha linguagem. Só quando falha a construção, é que obtenho o que ela não conseguiu" (Lispector, 1996, p. 133).

A escrita se escreve nesse deslizamento incessante de uma linguagem que não se diz nunca, uma linguagem que lhe dá o indizível, que lhe dá a medida do seu silêncio. Eloquente silêncio. Paradoxal escrita que fala se calando e que se cala falando. Ora a escrita não é o único modo de falar permanecendo em silêncio? Por meio desse silêncio, Ângela faz ouvir a existência oblíquo do feminino, mesmo se ela, como Macabea, "[...] se habitua lenta e muda e majestosamente e muito delicada e fatal - a ser mulher -, ela é muito modesta para sê-lo, ela é muito fugaz para ser definida" (Lispector, 1999, p. 68). O que, do feminino, não se reduz à ordem fálica pode existir somente assim obliquamente.

A escritura faz falar o feminino conforme ela toca o buraco no simbólico, o impossível, o real. Parece-nos que o gozo feminino, do qual Lacan fala no seminário "Encore", aproxima-se do que ele avança no seminário "A ética da psicanálise" (Lacan, 1986) como um outro modo de satisfação da pulsão: a sublimação. Essa satisfação, que não passa pelo recalcamento, situada no registro da sublimação, seria retomada, em 1975, a partir do Outro que não existe. $\mathrm{O}$ gozo feminino seria um modo de satisfação comparável àquele que Freud descreve na sublimação, não se tratando do recalcamento. O Outro aqui não é o código, o simbólico, o tesouro dos significantes, mas seu enigma, seu mistério, seu buraco. Não é nesse insondável da linguagem que Clarice se perde? Escrever não é outra coisa senão esse mergulho na matéria viva da língua.

O gozo feminino seria entendido como sublimação. Algumas escritas teriam relação com esse gozo. A escrita de Clarice não cessa de não se escrever, sempre relançada, adiada, inacabada. "O que te escrevo é um isto. Não vai parar: continua. [...] O que te escrevo continua e estou enfeitiçada" (Lispector, 1973, p. 259). Trata-se de uma escrita do impossível. São escritas que não são fálicas, nas quais se busca menos o sentido do que a música, fazendo surgir a voz como resto que cai atrás da significação. A escrita deixa assim cair o sentido para ser senão gozo. A estética do sopro em Clarice não é outra coisa senão essa escrita que se destaca do sentido, do significante, para não ser nada além de voz, sopro, respiração.

Os tremores do texto, as síncopes do sentido, as epifanias, os fugazes instantes, a perda e a ausência de si que se exibem na escrita clariciana nos 
conduzem a aproximar a sublimação de um gozo feminino e a compreender a primeira menos como elevação das pulsões do isso em direção aos ideais da cultura do que como fracasso do simbólico para dar conta do real. É pelo fracasso, que algo que se escreve, a sublimação aproximando-se menos de uma subjetivação do que de um désoeuvrement.

Refiro-me aqui ao termo blanchotiano que traduz a ideia de que a obra não é a afirmação do eu do escritor, mas, antes, seu rapto, sua perda, seu apagamento. Maurice Blanchot (1995a, 1995b, 1998) fala de um désoeuvrement do artista. A obra ignora o artista na afirmação impessoal que ela é. Ilegível para ele, a obra faz do artista um desocupado do qual a arte não depende. $\mathrm{O}$ escritor e a ignorância da obra, à qual ele está condenado, estão na contramão da ideia freudiana de sublimação definida como uma satisfação que não passa pelo recalque e que não pode então ser considerada como uma formação do inconsciente e, portanto, refere-se à consciência e ao eu. O escritor se eclipsa na escrita e aí desaparece. Submerso nas palavras, ele se torna outro (o que está longe de uma afirmação do eu). Dilacerado, destruído no imaginário da escrita, o escritor é um ser em suspensão. $\mathrm{Na}$ noção blanchotiana de désoeuvrement, trata-se mais de um rapto do eu do que da manifestação de um eu total e unificado.

A estética do sopro nos permite situar a sublimação do lado de um gozo não fálico, já que ela é uma satisfação da pulsão que não passa pelo recalcamento. O fundamento da sublimação não é outra coisa que o vazio central, tal é a definição dada por Lacan no seminário A ética da psicanálise. Criar a partir do vazio é a tarefa do artista. Ora, a escrita, como criação, seria um modo de relação com o vazio constitutivo do feminino. Nesse caso, a obra viria não tamponar o buraco deixado aberto por S (de A barrado), mas, ao contrário, viria desvelá-lo, revelá-lo.

O caminho traçado por Clarice privilegia a relação à $S$ (de A barrado), no qual a escrita pode ser o suporte de uma posição não toda na função fálica e pode se orientar em direção à mãe além da identificação paterna, abrindo a possibilidade de uma saída mais criativa à devastação da relação mãe-filha. A escrita seria assim um dos suportes do gozo feminino no mundo contemporâneo, tendo relação, ao mesmo tempo, ao falo e à falta no Outro.

O gozo feminino se manifesta em Clarice por meio de sua escrita, ela é o suporte da manifestação desse gozo, seu lugar de inscrição. Isso não quer dizer que ela está inteiramente nesse gozo, ela é não toda.

A escrita é pensada como um certo destino do feminino, um certo destino contingente do feminino impossível. Em seu seminário, "Encore", Lacan 
(1975) afirma que, das mulheres, nós só temos acesso ao semblante fálico (a histérica, a mãe, etc.). A análise não dá acesso à mulher e, nesse sentido, ela não existe. $\mathrm{O}$ único acesso, proposto por Lacan como impossível, é o gozo feminino. As manifestaçôes desse gozo é o que se ouve na estética do sopro de Clarice.

As mulheres têm uma relação privilegiada com o Outro e fazem suplência à ausência de relação sexual mais do lado do simbólico e do real do que do imaginário, contrariamente aos homens que, frequentemente, têm uma relação ao Outro regulada pelo falo e sob os auspícios do fantasma. Para as mulheres, a suplência não repousa sobre as representações imaginárias ou sobre os fantasmas. Ora, se a relação ao Outro que faz suplência à ausência de relação sexual se situa do lado do simbólico, nós temos aí um gozo que se suporta da linguagem. Trata-se assim de um gozo que passa pela palavra e sua lógica, mas que não pode se dizer, nem se elaborar em saber, o que quer dizer que se trata de uma relação ao real.

O que chama atenção na obra de Clarice não é o lado imaginário do objeto, as representações imaginárias ou mesmo o fantasma, mas o lado real do objeto, na sua relação com a falta no Outro, com o $S$ (de A barrado), o lado refratário do objeto ao simbólico. Clarice nos faz escutar uma suplência da inexistência da relação sexual do lado mulher que seria definida mais como simbólica e real do que como imaginária. Há, em sua obra, uma deflação do imaginário, mesmo se se trata de literatura. Daí a tensão da escrita, sua agonia, sempre em falta em relação ao que ela quer.

Em Clarice, há uma travessia da literatura, seus fantasmas e seu imaginário, em direção à "lituraterra", feita de restos e resíduos, uma travessia do significante à letra, assinalando o objeto além da letra. Ora a letra é o litoral, o que faz borda entre o simbólico e o real. Em busca de uma aproximação do real, Clarice tende em direção do limite da linguagem, despojando as palavras de todo sentido, de toda construção imaginária do sentido. Daí nossa hipótese: se há suplência pela escrita, trata-se de uma suplência menos da ordem do imaginário do que da ordem do simbólico e do real, mesmo quando se trata de literatura.

A obra pode ser entendida como o que tem relação com o que temos de mais singular, mas que permite o estabelecimento de um laço social, já que circula no simbólico. Nesse sentido, a obra faz laço social com o que nós temos de mais singular e é também um outro modo de pensar a relação das mulheres com o gozo fálico.

Para além das identificações imaginárias e simbólicas, como dar conta do 
real, dessa falha no centro do Outro, que faz com que nenhuma garantia possa ser esperada, mas que faz também que a partir deste ponto a criação possa surgir? Parece-nos que a estética do sopro tenta responder a essa questão. Dar existência a Ângela, a Joana, a G.H. ou a uma escrita-sopro são modos de fazer existir o feminino. Parece-nos que a escrita se constitui aqui como o que suporta o gozo feminino na sua relação a $S$ (de A barrado), ao mesmo tempo em que ela se refere ao falo.

Parece-nos que a arte pode ser o lugar privilegiado de manifestação desse gozo Outro. A escrita seria o suporte desse gozo suplementar, tendo relação com o falo e com $S$ (do Outro barrado). A escrita sustenta-se também no gozo fálico conforme ela pode inscrever o sujeito no pertencimento a um grupo, pode contribuir para a composição dos conjuntos e pode mesmo se definir em relação a uma bandeira (a literatura brasileira, francesa, italiana, etc.). De fato, é a própria Clarice quem nos fala do lado gregário da escrita e do desejo de pertencer como o que estava no começo de sua vocação de escritora. Que não nos surpreendamos de ver aí um fracasso, já que a escrita não a fará pertencer. A não satisfação é própria ao gozo fálico.

Entretanto, sua relação com a escrita não está toda nesse gozo fálico. Onde estaria esta parte que não se recobre pela função fálica? Quais poderiam ser as formas tomadas por S (de A barrado) na escrita de Clarice? Alguns termos podem corresponder, em Clarice, a este gozo (a solidão como parceira, a ausência de si mesma, a errância), seriam modos de relação com S (de A barrado), termos que corresponderiam a essa relação particular da mulher com o Outro.

Não somente a solidão de Joana, seu primeiro personagem, ponto isolado no mundo, ou a ausência de Laura, personagem do conto "A imitação da rosa”, ou ainda a errância de tantas mulheres escritas por Clarice são modos de relação a $S$ (de A barrado), mas também e sobretudo sua escrita errante, alusiva e silenciosa. Seu esforço para atingir o real desnudando as palavras de seus sentidos até as reduzir à pura sonoridade, a um ritmo, a um sopro, tem relação com este vetor em direção à $S$ (de A barrado). Clarice fala de despojamento, de renúncia, de queda. Ela se afasta da literatura tradicional para construir um saber em perda. As síncopes, os raptos, as epifanias são modos de manifestação deste real.

Ainda é preciso dizer que, se a suplência da relação sexual é simbólica, isso significa que se trata de um gozo que se suporta da linguagem. Em "Encore", Lacan afirma que o ser sexuado dessas mulheres não todas não passa pelo corpo, mas pelo que resulta de uma exigência lógica da palavra (Lacan, 1972- 
1973/1975). É essa lógica da palavra que se exibe na escrita de Clarice: um trabalho com a matéria linguageira que busca atingir o real (são as epifanias, os restos insignificantes de nossas existências, os instantes de ausência, a solidão, a errância, o silêncio) e, ao mesmo tempo, um esforço em se despojar do imaginário. Trata-se então de um gozo que passa pela palavra, mas que não pode se dizer.

Hoje se trata de se orientar, não em direção as místicas, mas em direção a uma certa relação com a criação a fim de saber um pouco mais sobre as manifestações desse gozo que não se reduz à lógica fálica. A estética do sopro em Clarice Lispector faz parte de uma concepção da arte na qual temos a música como linguagem sem palavras, a pintura livre de qualquer figura e a escrita liberada da palavra. Essa arte, orientada em direção ao Outro, não como tesouro de significantes, mas como enigma, segredo insondável, desenha-nos um certo destino do feminino no mundo contemporâneo.

\section{Referências}

Blanchot, M. (1995a). L'espace littéraire. Paris: Gallimard Folio Essais.

Blanchot, M. (1995b). Le livre à venir. Paris: Gallimard Folio Essais.

Blanchot, M. (1998). De Kafka a Kafka. Paris: Gallimard Folio Essais.

Charvet, J. L. (2000). Léloquence des larmes. Paris: Desclée de Brouwer.

Clément, C. (1990). La syncope: philosophie du ravissement. Paris: Bernard Grasset.

Lacan, J. (1986). Le séminaire livre VII L'étique de la psychanalyse. Paris: Seuil.

Lacan, J. (1975). Le séminaire livre XX Encore. Paris: Seuil.

Lacan, J. (1987). Lituraterre. Ornicar? Revue du Champ Freudien, 41 (12), $5-13$.

Lispector, C. (1973). Água viva: edição bilíngue. Paris: Des Femmes.

Lispector, C. (1996). A paixão segundo G. H.: edição crítica. Paris: UNESCO, Coleção Arquivos. 
Lispector, C. (1999). Um sopro de vida. Rio de Janeiro: Rocco.

Quignard, P. (1996). La haine de la musique. Paris: Folio Gallimard.

Quignard, P. (2000). Le nom sur le bout de la langue. Paris: Folio Gallimard. 